\title{
Applicants' Interest in International Ophthalmology during Residency Training: Influence in Selecting U.S. Residency Programs
}

\author{
Mona L. Camacci, MD, MS ${ }^{1}$ David A. Quillen, MD ${ }^{1} \quad$ Maria Montijo ${ }^{1} \quad$ Michael C. Chen, MD ${ }^{1}$ \\ ${ }^{1}$ Department of Ophthalmology, Penn State College of Medicine, \\ Hershey, Pennsylvania \\ Journal of Academic Ophthalmology 2018;10:e48-e54.

\begin{abstract}
Address for correspondence Michael C. Chen, MD, Department of Ophthalmology, Penn State College of Medicine, 500 University Drive, HU19, Hershey, PA 17033-0850
\end{abstract} \\ (e-mail: mchen3@pennstatehealth.psu.edu).
}

\begin{abstract}
Background In recent years, the Accreditation Council for Graduate Medical Education (ACGME) Residency Committee for Ophthalmology formally recognized international health electives for credit. By engaging in international health experiences, ophthalmology residents achieve the anchors essential to the core competencies set forth by the ACGME. Objective To explore how the availability of international ophthalmology opportunities may influence applicants' selection of U.S. ophthalmology residency programs and to identify applicants' perceived goals and barriers of participation in international ophthalmology experiences.

Methods For this cross-sectional study, an electronic invitation to a 22-item questionnaire was sent to all 413 applicants to the ophthalmology residency program at the Penn State Eye Center during the 2017 Match.

Results Responses were received from 261 applicants, yielding a response rate of $63.2 \%$. Nearly all respondents $(95.4 \%)$ reported interest in participating in an international ophthalmology experience during residency training, with $52.1 \%$ of respondents reporting being "extremely interested." More than half of respondents $(53.6 \%)$ had previously participated in a healthcare-related experience in an international setting. The availability of international opportunities increased the interest of $67.4 \%$ of respondents when choosing which residency programs to apply to, and influenced $65.2 \%$ of respondents to rank a residency program higher, with the respondents with previous international experience more likely to be favorably influenced $(p<0.001$, $p=0.04$, respectively). The goal identified by the largest number of respondents as "most important" was to "offer service to the underserved" (59.0\%). The most

Keywords

- residency program

- ophthalmology education

- ophthalmology

- international ophthalmology

- global health

- international health electives commonly identified anticipated barriers to participating in an international experience during residency training included concern about scheduling conflicts and call coverage $(81.7 \%)$, followed by lack of funding $(71.4 \%)$.

Conclusion There is significant interest in international ophthalmology among ophthalmology residency applicants, and the availability of international opportunities during training may influence the applicants' selection of programs. Statistically significant differences were found among respondents with and without previous international healthcare-related experience. These findings warrant further investigation into how residency programs can best address this interest and integrate international ophthalmology experiences into the residency curriculum.
\end{abstract}

received

January 26, 2018 accepted after revision March 6, 2018
DOI https://doi.org/

10.1055/s-0038-1641610. ISSN $2475-4757$.
Copyright $\odot 2018$ by Thieme Medical

Publishers, Inc., 333 Seventh Avenue, New York, NY 10001, USA Tel: +1(212) 584-4662.
License terms

(요 (1) $\Theta \circledast$ 
With increasing international travel and immigration, widening inequalities in healthcare around the world, and occurrences of multinational epidemics, the topic of global health is growing in importance and popularity among healthcare providers. ${ }^{1-3}$ Currently, more than a quarter of graduating U.S. medical students have participated in some form of global health experience prior to starting residency training. ${ }^{4}$ International health training has become an increasingly important aspect of U.S. resident education. ${ }^{3}$ Studies have shown high levels of interest in international experiences in specialties such as emergency medicine, ${ }^{5}$ general surgery, ${ }^{6}$ and pediatrics. ${ }^{7}$ By engaging in international health experiences, residents achieve the anchors essential to the core competencies set forth by the Accreditation Council for Graduate Medical Education (ACGME), including patient care, medical knowledge, practice-based learning and improvement, systems-based practice, professionalism, and interpersonal skills and communication. ${ }^{8-13}$

Ophthalmologists are positioned as leaders in global health in part due to the field's longstanding efforts to address preventable and treatable blindness worldwide. ${ }^{14-17}$ In July 2013, the ACGME Residency Committee for Ophthalmology formally recognized international health electives by allowing credit for up to 1 month for an international ophthalmology rotation. ${ }^{18}$ In a recent study, Coombs and colleagues found that the majority (83\%) of U.S. ophthalmology training programs surveyed currently participate in some form of global health. ${ }^{19}$ Moreover, 63\% of the program directors surveyed believed global health was important to medical students when evaluating ophthalmology residency programs. ${ }^{19}$

This current study explores this topic from the applicants' perspective, by exploring how the availability of international ophthalmology opportunities may affect the selection of ophthalmology residency programs in the application and ranking process. This study also explores applicants' perceived goals and barriers regarding participation in international ophthalmology experiences during residency training.

\section{Materials and Methods}

An electronic invitation to an online survey was sent to all 413 applicants to the ophthalmology residency program at the Penn State Eye Center during the 2017 Ophthalmology Match. A small financial incentive (\$5 Amazon gift card) was offered for the completion of the survey. Participants anonymously completed a 22-item questionnaire that included multiplechoice and Likert-scale questions (see Supplementary Material). Responses were collected over a 5-week time period (March 10, 2017, to April 15, 2017). A weekly reminder was sent to those who had not completed the survey. Study data were collected and managed using REDCap electronic data capture tool hosted at the Penn State Hershey Medical Center. ${ }^{20}$ Statistical analysis was performed using SAS version 9.4 (SAS Institute Inc., Cary, NC). Chi-squared tests were used for categorical variables and two-sample $t$-tests were performed on the assessment of Likert-scale questions to assess the relationship between previous international health experience and applicant survey responses. $p$-Values less than 0.05 were considered statistically significant for all analyses. This study was deemed exempt by the Penn State Hershey Institutional Review Board.

\section{Results}

Reponses were received from 261 applicants, yielding a response rate of $63.2 \%$. Of the applicants who responded, 85.8\% (224) successfully matched with an ophthalmology residency program in the 2017 Ophthalmology Match.

\section{Interest in International Opportunities during Residency}

The majority of respondents $(95.4 \%, 249)$ were interested in participating in an international ophthalmology experience during residency, with 52.1\% (136) of respondents reporting being "extremely interested" (-Fig. 1). Roughly half (53.6\%, 140 ) of all respondents had previously participated in an international healthcare-related experience. Of these respondents, $40.7 \%$ (57) had previously participated in an international experience related to eye care. The most common type of previous international healthcare-related experience was "mission or charity service trips" (70.0\%, 98).

\section{Influence on Residency Program Application and Ranking}

Roughly two-thirds of the respondents $(67.4 \%, 176)$ reported that the presence of an international opportunity in ophthalmology increased their interest in applying to a residency program. When ranking programs, the presence of an international opportunity positively influenced 65.2\% (148) of respondents. Respondents who had prior international healthcare-related experience were more likely to be positively influenced, compared with those without prior experience, by the presence of international opportunities in choosing which programs to apply to ( 81.4 vs. $51.3 \%, p<0.001)$ and in the ranking of programs for the Match ( $p=0.04$; - Fig. 1). Of matched respondents, $39.1 \%$ (102) reported that their matched program offered international opportunities. The type of opportunities most commonly reported were mission or charity service trips $(62.7 \%, 64)$, followed by an ophthalmology surgical elective at a training institution $(45.1 \%, 46)$.

\section{Anticipated Goals and Barriers}

When asked about goals and opportunities abroad, more respondents consistently ranked goals related to service and teaching higher than goals related to learning. Fifty-nine percent of respondents (154) ranked "offer service to the underserved" as the most important goal for an international ophthalmology experience. More than two-thirds of respondents $(69.0 \%, 180)$ ranked "educate and train national eye care provider(s)" higher than "learning from national eye care providers" (-Fig. 2). Similarly, when ranking educational and clinical opportunities, "performing surgery" $(55.2 \%, 144)$ or "examining and treating patients in clinic" $(31.4 \%, 82)$ was identified by more respondents as most important, over "observing another eye care system and interacting with national eye care providers" $(11.9 \%, 31)$. 

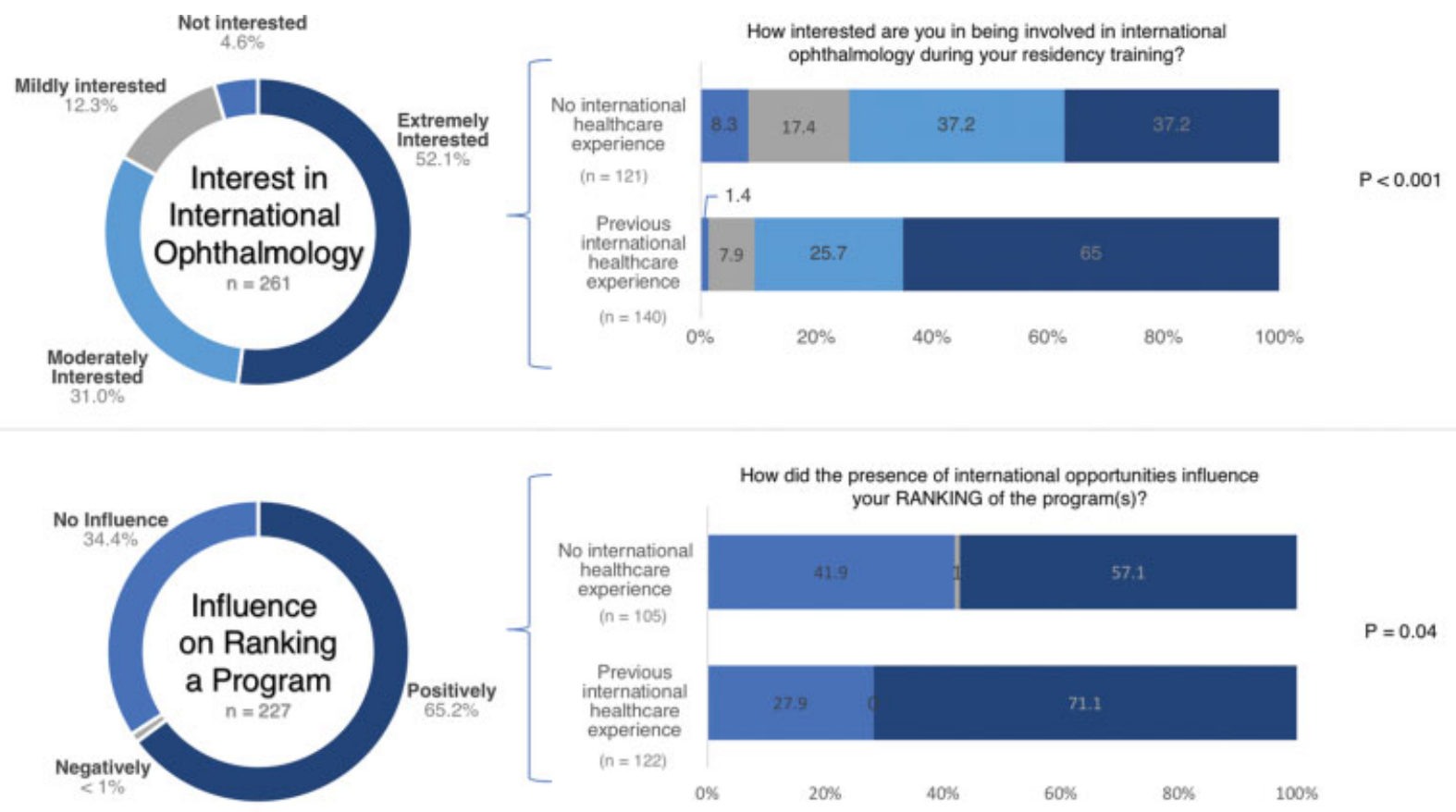

How did the presence of international opportunities influence
your RANKING of the program(s)?
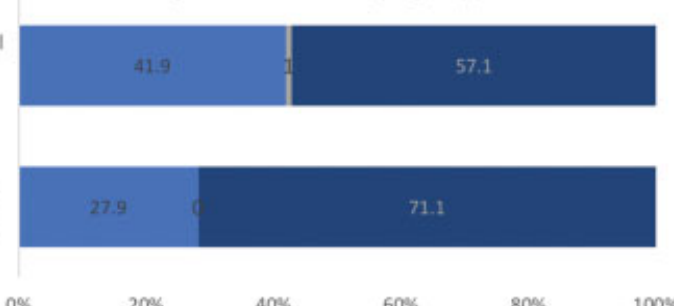

$P=0.04$
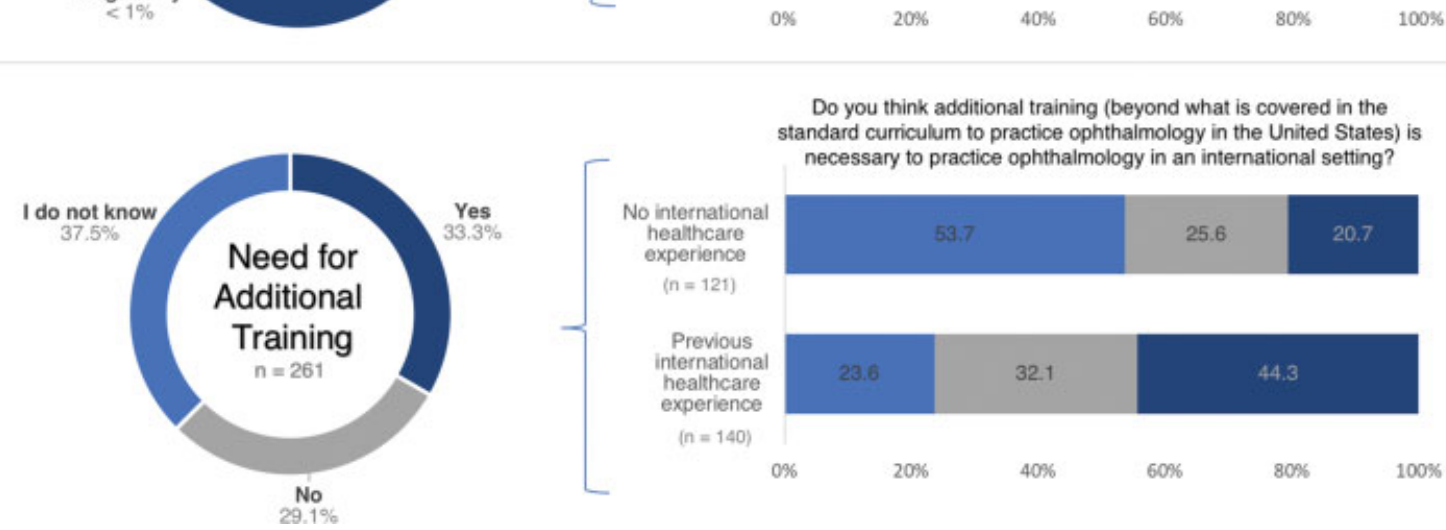
necessary to practice ophthalmology in an international setting?

Fig. 1 Comparing responses to three survey questions from respondents with and without prior international healthcare-related experience. Figures on the left depict responses of both subgroups combined, and figures on the right depict responses of each subgroup. Statistically significant $p$-values $(<0.05)$ obtained from two-sample $t$-tests are shown.

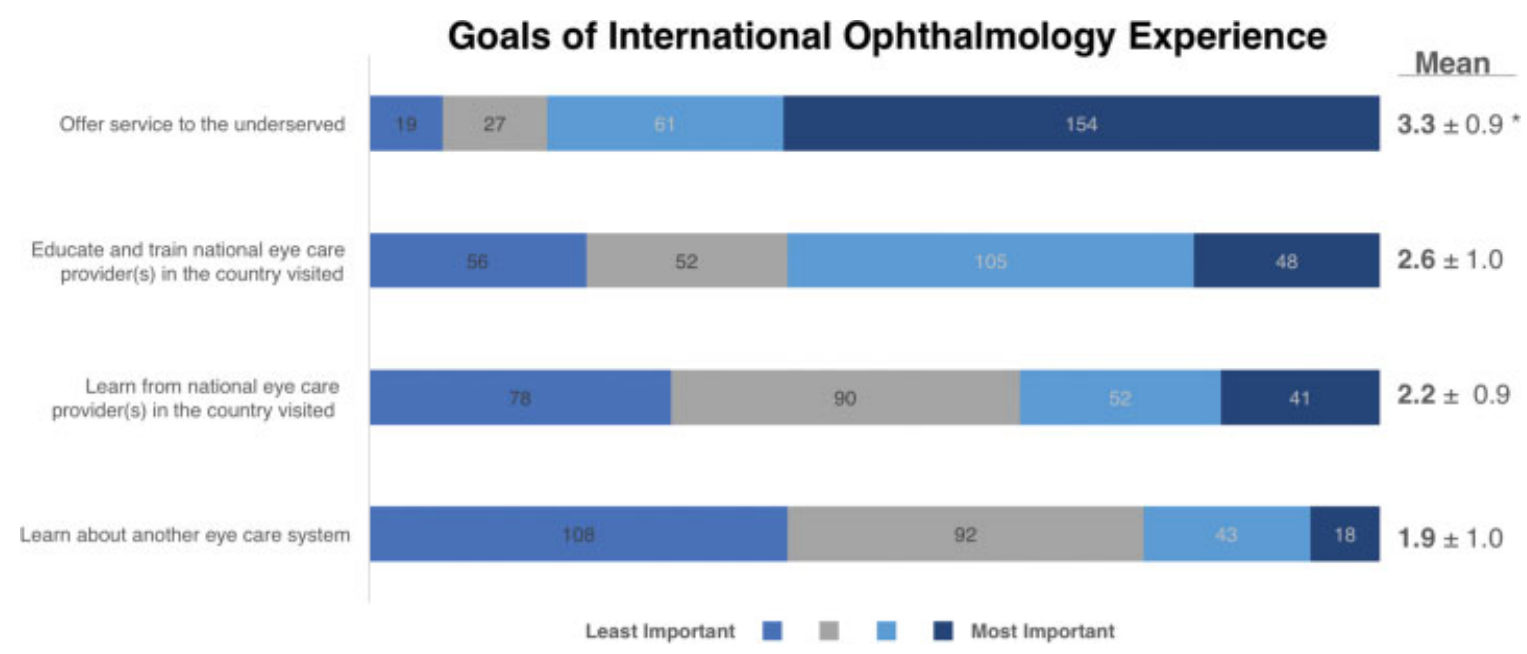

Fig. 2 Responses to the survey question, "Of the possible objectives given, which would you consider to be most important in an international experience during residency? Rank in order." Number of respondents, mean, and standard deviation values are shown $(n=261)$. Statistically significant $p$-values $(<0.05)$ obtained from two-sample $t$-tests comparing respondents with and without previous international healthcarerelated experience are shown with an asterisk. ${ }^{*}$ Offer service to the underserved (mean 3.22 vs. 3.48, respectively; $p=0.03$ ). 


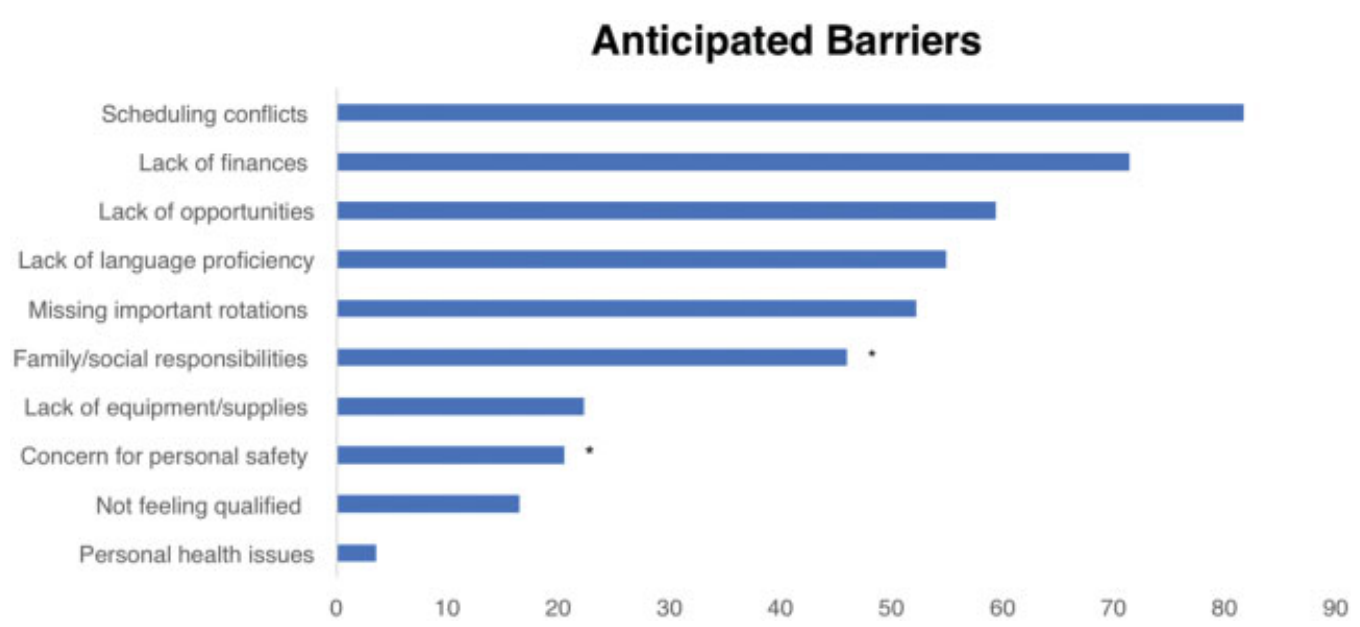

Fig. 3 Responses to the survey question, "What type of barriers do you anticipate encountering during residency that may prevent you from participating in an international ophthalmology experience? Check all that apply" $(n=224)$. Statistically significant $p$-values $(<0.05)$ were obtained from two-sample $t$-tests comparing respondents with and without previous international healthcare-related experience and are shown with an asterisk. *Family/social responsibilities (32.9 vs. $47.1 \%$, respectively, $p=0.02$ ); concern for personal safety (11.4 vs. $24.8 \%$, respectively, $p=0.005$ ).

Only $2.2 \%$ (5) of respondents reported that they did not anticipate any barriers to participating in an international ophthalmology experience. Regarding logistics, 31.4\% (82) of the participants reported that the funding of an international experience was the most important factor. The majority $(81.7 \%, 183)$ of respondents reported that scheduling and call coverage was the most significant anticipated barrier, followed by lack of finances $(71.4 \%, 160)$. Other foreseen barriers to participating in an international ophthalmology experience during residency, identified by more than half of all respondents, were lack of opportunities in a residency program $(59.4 \%, 133)$, lack of language proficiency $(54.9 \%$, 123), and missing an important component of a rotation at their home institution (52.2\%, 117; - Fig. 3).

\section{International Ophthalmology Curriculum}

Of the participants who were interested in pursuing an international experience during residency, 96.8\% (243) responded that an orientation would be helpful prior to traveling abroad, with a one-on-one briefing with an attending $(51.0 \%, 128)$ for a half-day $(56.4 \%, 137)$ the most commonly chosen orientation type and length. Nearly all of the participants $(93.4 \%, 239)$ reported that 2 to 4 weeks would be the optimal length of time devoted to an international ophthalmology experience.

A third of the respondents $(33.3 \%, 87)$ reported that additional training (beyond what is covered in a standard curriculum to practice ophthalmology in the United States) is necessary to practice ophthalmology in an international setting. Of the remainder, $37.5 \%$ (98) were unsure, and $29.1 \%(76)$ did not think that any additional training is necessary (-Fig. 1). The most commonly identified areas of additional training needed were "surgical techniques" $(63.2 \%, 55)$, "cross-cultural interactions" (50.6\%, 44), and "healthcare systems" (33.3\%, 29; - Fig. 4). Compared with respondents who did not have prior international healthcare-related experience, respondents who had were more likely to think that additional training is necessary (20.7 vs. $44.3 \%$, respectively, $p<0.001$; - Fig. 1 ).

\section{Additional International Health Training}

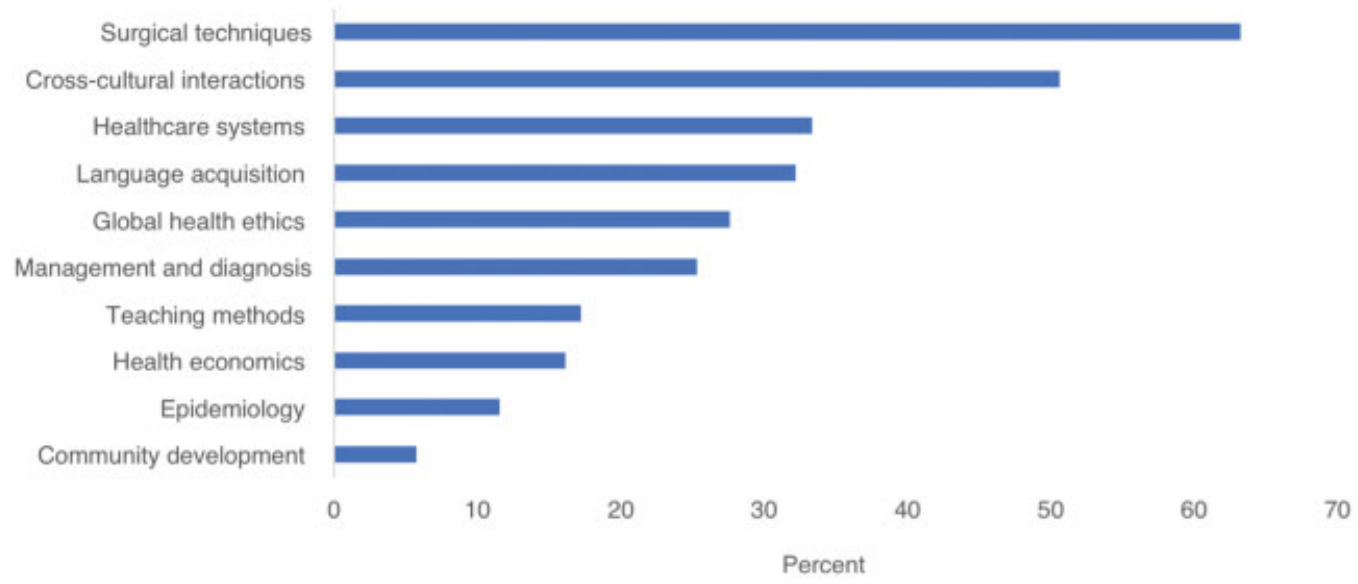

Fig. 4 Respondents who answered that additional training was needed were asked, "What type of additional training is most needed? Please check up to three" $(n=87)$. 


\section{Discussion}

Applicant's Interest in International Ophthalmology An overwhelming majority of ophthalmology residency program applicants responding to the survey expressed interest in participating in an international ophthalmology experience during their residency training. Approximately two-thirds of respondents were positively influenced by the presence of international opportunities both in choosing which programs to apply to and in the ranking of programs. Similar findings have been reported in other specialties. ${ }^{5-7}$ Interestingly, more than half of our respondents had previous international healthcare-related experience, which is almost double the percentage for all medical students as reported in 2017 by the Association of American Medical Colleges (AAMC). ${ }^{4}$ This seems to suggest that the field of ophthalmology draws a disproportionate share of medical students who are interested in international health, which may be explained by the field's longstanding efforts to address preventable and treatable blindness worldwide. ${ }^{14-17}$

\section{Perceived Goals in an International Ophthalmology Experience}

In this study, respondents generally ranked goals related to service and teaching higher than goals related to learning. Goals such as "offer service to the underserved," "educate and train national eye care provider(s)," "performing surgery," and "examining and treating patients in clinic" were chosen more often over goals such as "learning from national eye care providers" and "observing another eye care system and interacting with national eye care providers." The focus on service and teaching over learning may be explained by the respondent's perception of the opportunities available to them both prior to and during residency. Among those who had participated in an international healthcare-related experience by the time of the survey, more than two-thirds of applicants reported having previous international experience through a mission or charity service trip. The most common type of opportunity offered at their matched institution was mission or charity service trips. It is therefore not unexpected that the predominant perception of the role among respondents was more of a provider rather than a learner.

\section{Challenges to Participation in International Ophthalmology Opportunities}

While international ophthalmology opportunities are attractive to the majority of residency applicants who responded to this survey, residency programs need to be mindful of the potential challenges that international experiences pose for both residency programs and trainees. Coombs and colleagues found that among the ophthalmology residency program directors surveyed, the top two perceived obstacles identified were inadequate financial support and inadequate resident coverage at the home institution. ${ }^{19}$ Similarly, scheduling conflicts in work or call coverage and lack of finances were the anticipated barriers most commonly cited by the respondents in this study. Another anticipated barrier cited by more than half the respondents in this study was the concern over missing an important component of a rotation at the home institution, highlighting the importance of ensuring equivalency in education and proper supervision when trainees are abroad.

\section{Differences in Respondents with Previous International Healthcare-Related Experience}

As may be expected, those who had prior international healthcare-related experience were statistically more likely to respond that they were "extremely interested" in participating in an international ophthalmology experience during residency when compared with those who did not have prior experience. In addition, those having prior experience were more likely to be positively influenced by the presence of international opportunities both in choosing which programs to apply to and in the ranking of programs.

Our findings also suggest that the experienced subgroup may be more likely to be aware of the complex issues that exist in the global health setting and may have more realistic expectations for the goals and barriers of taking part in an international opportunity during residency. Respondents with previous experience were less likely to select "offer service to the underserved" as the most important goal when compared with respondents with no previous experience, and were also more likely to think that additional training is necessary to practice ophthalmology in an international setting.

\section{Opportunities to Shape International Ophthalmology Education}

The findings of this study demonstrate that applicants have strong interest in international ophthalmology opportunities during their residency training. As ophthalmology residents can now receive credit for international electives, there is a need for standardized goals and guidelines for what an international elective should entail. Other specialties have begun to develop standards to ensure residents are gaining specific core competencies as part of their international experience. $^{21}$ This need for well-defined objectives provides great opportunity for the academic ophthalmology community to thoughtfully create structured curricula based on core competencies with realistic goals and expectations.

The findings of this study also suggest that ophthalmology residency applicants, in general, are more focused on service and teaching rather than learning in their anticipated participation in international experiences. Notably, only onethird of respondents thought that additional training, beyond what is covered in the standard curriculum to practice ophthalmology in the United States, is necessary to practice ophthalmology in an international setting. While we applaud the motive of service to the underserved, we believe that residency programs need to emphasize the importance of humility and the participants' role as learners rather than providers when participating in international experiences during residency training. One of the primary objectives of incorporating international experiences during residency training is to expose trainees to the realities of practicing ophthalmology in settings different from the 
United States. These differences could include aspects related to resource availability, healthcare coverage, socioeconomics, cultural factors, clinical pathologies, and surgical techniques that may enable or necessitate a different approach to the delivery of eye care. This exposure allows trainees to step outside of the U.S. healthcare system, inviting comparisons between the resident's home institution and the international site. This critical appraisal could identify areas for improvement of either system, inspiring the next generation of innovation in eye care delivery. The ability to learn from systems that are different from one's own is a vital skill not only during training but during any stage of career, and is essential to carrying out effective service whether in the United States or abroad.

\section{Limitations}

This study has several limitations, one being the partial response rate. This being said, our response rate of $63.2 \%$ is higher than the rates reported in other similar surveys on residency applicants. ${ }^{22,23}$ Inherent to surveys with partial response rates, limitations include potential biases in recall, response, and sampling. To minimize recall bias, questionnaires were administered shortly after the Match in the Spring of 2017. Among those who responded, there may be a response bias, with those interested in international ophthalmology being more likely to respond than those who were not interested. It is also possible that the results of this study do not capture the sentiment of the entire applicant pool of the San Francisco Ophthalmology Match ( $n=657)$, in that this study surveyed only applicants who applied to the residency program at the Penn State Eye Center $(n=413)$, and only 261 of these applicants responded to the survey. This being said, taking the unlikely extreme scenario that all applicants in the San Francisco Ophthalmology Match who were not captured in this survey were uninterested in participating in an international ophthalmology experience during training, with the 249 respondents who expressed interest in this survey, at a minimum $37.9 \%$ of the entire applicant pool, or approximately two out of every five applicants, are interested.

\section{Conclusion}

In conclusion, there is significant interest in international ophthalmology among applicants to ophthalmology residency programs, and the availability of international opportunities during training may influence the applicants' selection and ranking of programs. These findings warrant further investigation into how residency programs can best address this interest and integrate international ophthalmology training into the residency curriculum. While service to the underserved appears to be the primary motivation for many applicants, residency program leaders have the opportunity to thoughtfully create structured curricula based on ACGME core competencies with realistic goals and expectations, and to set a foundation for lifelong learning that will be applicable toward practicing ophthalmology both in the United States and internationally. The findings in this study suggest that applicants with prior international healthcare-related experience may have different perspectives and expectations regarding their participation in international ophthalmology experiences. Future studies are necessary to evaluate the outcomes of international ophthalmology training on resident education and to confirm how residents' participation in international ophthalmology experiences during training may influence perspectives and expectations of participation in international ophthalmology in their future careers.

\section{Funding}

This study was funded by the Department of Ophthalmology, Penn State College of Medicine, Hershey Pennsylvania; the Penn State Clinical and Translational Research Institute, Pennsylvania State University CTSA, NIH/NCATS grant numbers UL1 TR000127 and UL1 TR002014.

\section{Conflict of Interest}

None declared.

\section{References}

1 Houpt ER, Pearson RD, Hall TL. Three domains of competency in global health education: recommendations for all medical students. Acad Med 2007;82(03):222-225

2 Battat R, Seidman G, Chadi N, et al. Global health competencies and approaches in medical education: a literature review. BMC Med Educ 2010;10(01):94

3 Drain PK, Holmes KK, Skeff KM, Hall TL, Gardner P. Global health training and international clinical rotations during residency: current status, needs, and opportunities. Acad Med 2009;84(03):320-325

4 Association of American Medical Colleges. Medical School Graduation Questionnaire 2017 All Schools Summary Report; 2017

5 Dey CC, Grabowski JG, Gebreyes K, Hsu E, VanRooyen MJ. Influence of international emergency medicine opportunities on residency program selection. Acad Emerg Med 2002;9(07):679-683

6 Powell AC, Mueller C, Kingham P, Berman R, Pachter HL, Hopkins MA. International experience, electives, and volunteerism in surgical training: a survey of resident interest. J Am Coll Surg 2007;205(01):162-168

7 Federico SG, Zachar PA, Oravec CM, Mandler T, Goldson E, Brown J. A successful international child health elective: the University of Colorado Department of Pediatrics' experience. Arch Pediatr Adolesc Med 2006;160(02):191-196

8 Sawatsky AP, Rosenman DJ, Merry SP, McDonald FS. Eight years of the Mayo International Health Program: what an international elective adds to resident education. Mayo Clinic Proc 2010;85(08): 734-741

9 Hau DK, Dipace JI, Peck RN, Johnson WD Jr. Global health training during residency: the Weill Cornell Tanzania experience. J Grad Med Educ 2011;3(03):421-424

10 Volsky PG, Sinacori JT. Global health initiatives of US otolaryngology residency programs: 2011 global health initiatives survey results. Laryngoscope 2012;122(11):2422-2427

11 Anspacher M, Frintner MP, Denno D, et al. Global health education for pediatric residents: a national survey. Pediatrics 2011;128 (04):e959-e965

12 Haq C, Rothenberg D, Gjerde C, et al. New world views: preparing physicians in training for global health work. Fam Med 2000;32 (08):566-572

13 Evert J, Stewart C, Chan K, Rosenberg M, Hall T. Developing Residency Training in Global Health: A Guidebook. San Francisco, CA: Global Health Education Consortium; 2008 
e54 Applicants' Interest in International Ophthalmology during Residency Training Camacci et al.

14 Pascolini D, Mariotti SP. Global estimates of visual impairment: 2010. Br J Ophthalmol 2012;96(05):614-618

15 Bourne RR, Stevens GA, White RA, et al; Vision Loss Expert Group. Causes of vision loss worldwide, 1990-2010: a systematic analysis. Lancet Glob Health 2013;1(06):e339-e349

16 Tabin G, Chen M, Espandar L. Cataract surgery for the developing world. Curr Opin Ophthalmol 2008;19(01):55-59

17 Khairallah M, Kahloun R, Bourne R, et al; Vision Loss Expert Group of the Global Burden of Disease Study. Number of people blind or visually impaired by cataract worldwide and in world regions, 1990 to 2010. Invest Ophthalmol Vis Sci 2015;56(11): 6762-6769

18 Accreditation Council for Graduate Medical Education. ACGME Program Requirements for Graduate Medical Education in Ophthalmology; 2017. Available at:https://www.acgme.org/Portals/0/PFAssets/ProgramRequirements/240_ophthalmology_201707-01.pdf. Accesssed January 26, 2018
19 Coombs PG, Feldman BH, Lauer AK, Paul Chan RV, Sun G. Global health training in ophthalmology residency programs. J Surg Educ 2015;72(04):e52-e59

20 Harris PA, Taylor R, Thielke R, Payne J, Gonzalez N, Conde JG. Research electronic data capture (REDCap): a metadata-driven methodology and workflow process for providing translational research informatics support. J Biomed Inform 2009;42(02): 377-381

21 Hayden SR, Valderrama CM, Xu M, Curran MA, Mazondo R, Soliman MA. Development of an international elective in an emergency medicine residency. J Emerg Med 2016;50(01):153-158

22 Yousuf SJ, Kwagyan J, Jones LS. Applicants' choice of an ophthalmology residency program. Ophthalmology 2013;120(02):423-427

23 Davydow D, Bienvenu OJ, Lipsey J, Swartz K. Factors influencing the choice of a psychiatric residency program: a survey of applicants to the Johns Hopkins Residency Program in Psychiatry. Acad Psychiatry 2008;32(02):143-146 